Submission ID: 43836

\title{
Three-Dimensional Density Model of Enisey-Khatanga-Region
}

I.V. Lygin* (Moscow State University), A.P. Afanasenkov (VNIGNI, Moscow State University), T.B. Sokolova (Moscow State University), K.M. Kuznetsov (Moscow State University), G.S. Grigoriev (Moscow State University)

\section{SUMMARY}

Yenisei-Khatanga regional trough (the borderland of the Siberian platform) is poorly studied area by seismic method. At the same time, the territory is more than $70 \%$ covered by gravity and magnetic. In this case high efficiency of integration based on the analysis and interpretation of gravity and magnetic fields is evidence.

Joint interpretation of potential fields data and seismic data has allowed to clarify the structure of seismic horizons in space between seismic lines and offer original underlying three-dimensional density and magnetic model of the earth's crust. These models made new insight on the geological structure and geological history of the region. The key result was a volumetric reconstruction of the tectonic elements of the Yenisei-Khatanga rift system. The technique of creating three-dimensional density model and its use in geological reconstructions is in this report. 


\section{Трехмерная геоплотностная модель Енисей-Хатангского региона}

И.В. Лыгин * (МГУ имени М.В. Ломоносова), А.П. Афанасенков (ФГБУ "ВНИГНИ", МГУ имени М.В. Ломоносова), Т.Б. Соколова (МГУ имени М.В. Ломоносова), А.Н. Обухов (ФГБУ "ВНИГНИ"), К.М. Кузнецов (МГУ имени М.В. Ломоносова), Г.С. Григорьев (МГУ имени М.В. Ломоносова)

\section{Введение}

Енисей-Хатангский региональный прогиб (ЕХРП) в силу высокого углеводородного потенциала в 2012-2016 годах стал объектом крупного проекта по изучению ресурсов слабоизученных территорий северного обрамления Сибирской платформы (Афансенков и др., 2017). ЕХРП имеет весьма сложное геологическое строение, и, несмотря на достаточно длительную историю геолого-поисковых работ, характеризуется весьма неоднородной по детальности и методам исследования степенью изученности. Так изученность методами сейсморазведки (МОВ-ОГТ) отвечает региональной стадии: расстояния между профилями в центральной части в среднем составляют 50 км, а краевые северная и южная зоны прогиба и примыкающие к ним орогенные области Таймыра и севера средне-Сибирского плоскогорья не покрыты сейсморазведкой вовсе. В то же время, территория более чем на 70 \% покрыта гравиметрическими и магнитными съемками. В этой ситуации очевидной становится высокая эффективность комплексирования с опорой на анализ и интерпретацию потенциальных (гравитационного и магнитного) полей.

Данные гравиразведки и магниторазведки применены для определения физико-геологических, тектонических, динамических условий, создания схемы геотектонического районирования региона, анализа дизъюнктивной тектоники, выделения, классификации и систематизации тектонических нарушений. Совместная интерпретация данных потенциальных полей и сейсморазведки позволила не только дополнить и уточнить структуру сейсмических горизонтов в межпрофильном пространстве, но и предложить оригинальные глубинные трехмерные плотностные и магнитные модели земной коры. Эти модели, построенные на уточненном сейсмическом каркасе, заставили по-новому взглянуть на геологическое строение и историю развития региона. Ключевым результатом стала объемная реконструкция тектонических элементов Енисей-Хатангской рифтовой системы (Афансенков и др., 2017).

В данном сообщении изложена методика создания трехмерной плотностной модели и её использование при геологических реконструкциях.

\section{Методика составления трехмерной плотностной модели}

В ходе подготовки к моделированию источников гравитационных аномалий проведено обобщение априорных данных комплексных геологических и геофизических исследований, включившее базовую информацию прямых геологических методов, бурения, результаты современной интерпретации 2Д сейсморазведки, структурный анализ актуализированных карт исходных потенциальных полей и их трансформант.

Начальным, и очень ответственным, этапом является создание предварительной плотностной модели, от полноты и представительности которой во многом зависит конечный результат. Физические свойства (плотность) горных пород обобщены как по региональным работам на изучаемой территории и её обрамлении: Восточная и Западная Сибирь, побережье Карского моря (Гыдан, Таймыр), так и по данным плотностного каротажа редких скважин ЕнисейХатангского региона. Данные плотностного каротажа приведены на сводном плотностном разрезе (рисунок 1), они иллюстрируют высокую плотностную изменчивость стратиграфических комплексов по латерали. 


\section{EAGE \\ 대을 Геомодель-2017}

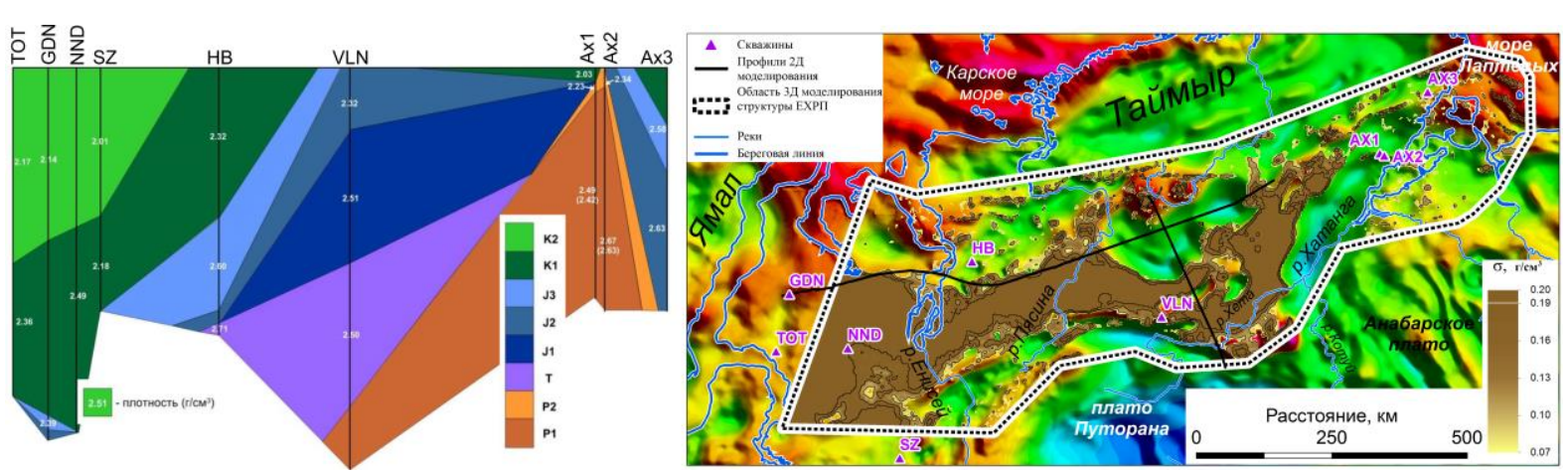

Рисунок 1 Схема корреляции плотностей по данным каротажа скважин Енисей-Хатангского и Хатангско-Ленского бассейнов (слева) и Аномальные плотности верхней части земной коры на фоне региональных аномалий силь тяжести в редукиии Буге (справа). Для нижнепермских отложений в скобках обозначена плотность пород слоя без учета магматических образований $\beta T_{l} b$.

На следующем этапе, с целью выявления основных плотностных закономерностей разреза, необходимых для параметризации трехмерной плотностной модели, выполнено интерактивное двумерное плотностное моделирование вдоль двух опорных профилей в центре площади исследования. В основу двумерных моделей, помимо сводных данных о плотности, заложена структурная интерпретация 2Д сейсморазведки. В нижнюю часть разреза включены три слоя верхняя и нижняя кора и мантия. Кровля верхней мантии (граница Мохо) задана согласно оценкам В.С. Суркова (2007). Плотности в верхней части разреза не подбирались и приняты постоянными (выше кровли палеозоя). Сведения о подошве осадочного чехла (кровли фундамента) отрывочные: на сейсмических профилях корреляции фрагментарные. При моделировании выполнена попытка восстановления данной границы, однако её прослеживание является крайне неоднозначной операцией даже при двумерном плотностном моделировании.

Основными результатами этапа двумерного плотностного моделирования являются:

- для учета гравитационных эффектов, наблюдаемых над Енисей-Хатангским бассейном, необходимо вводить плотностную дифференциацию верхней мантии, варьировать формами основных глубинных границ (Мохо и кровля нижней коры) и существенно уплотнять комплексы в его основании;

- наиболее плотные породы коры и верхней мантии находятся в бортовых частях бассейна;

- Янгодо-Горбитский выступ и Балахнинский вал выделяются в осадочной толще ЕХРП аномально высокими значениями (латеральная неоднородность) плотности.

При расчете и анализе трансформаций гравитационного поля, в том числе с использованием алгоритмов, построенных на Вейвлет-преобразованиях (Кузнецов и др., 2015), была отмечена корреляционная связь морфологии локальных аномалий и структуры поверхности сейсмостратиграфических комплексов верхней части осадочного чехла. Более высокая детальность гравиметрических данных позволила на основе рассчитанных корреляционностатистических связей выполнить коррекцию самого контрастного по плотности сейсмического горизонта в межпрофильном пространстве. Однако следует отметить, что в полученной границе частично заложены латеральные плотностные изменения верхней осадочной толщи (гравитационные эффекты которых имеют прямую корреляцию с гравитационным полем) и на текущей стадии исследований исключены быть не могут.

Трехмерное плотностное моделирование выполнено в три этапа. На первом этапе из аномального гравитационного поля в редукции Буге исключены гравитирующие эффекты известных плотностных границ. Уже на этом этапе, в остаточном гравитационном поле, наиболее яркой и интенсивной положительной аномалией выделились высокоплотные элементы внутреннего строения ЕХРП. Резкими контрастными гравитационными ступенями четко обозначились внешние глубинные латеральные границы Енисей-Хатангской зоны. В общей структуре обращает на себя внимание достаточно сложная конфигурация центральной 
зоны. Во всех направлениях, кроме западного, аномальная зона замыкается. В отдельных крайних точках яркими положительными аномалиями подчеркиваются узловые тектонические элементы: Гулинский массив, северная граница Янгодо-Горбитского выступа, восточное окончание Енисей-Хатангской рифтовой зоны и др. Следует обратить внимание на отсутствие в западной части рассматриваемого региона (вблизи р.Енисей) в остаточных аномалиях гравитационного поля градиентных зон, что позволяет сделать вывод о единстве КолтогорУренгойской и Енисей-Хатангской рифтовых структур.

На втором этапе по остаточному полю выполнен подбор распределения аномальных плотностей в верхней мантии и земной коре ниже кровли палеозоя. На последнем, третьем, этапе - подбор плотностей в толщах выше кровли палеозоя.

Интервал от поверхности Мохо до кровли палеозоя разбит на три слоя: нижняя кора, верхняя кора, включающая кристаллический фундамент, и нижняя часть осадочного чехла (допалеозойская).

Верхняя мантия сверху ограничена моделью горизонта Мохо В.С.Суркова (2007), которая при моделировании остается неизменной, снизу - горизонтальной поверхностью 60 км. В слое

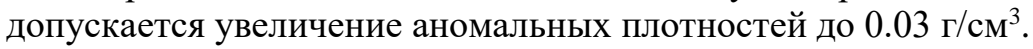

Граница между нижней и верхней корой проведена на глубине 20 км согласно средним оценкам по данным ГСЗ, построениям В.С Суркова (2007), опыту моделирования на сопредельных территориях. На границе принят скачок плотностей 0.20 г/ $\mathrm{cm}^{3}$. При подборе в слое допускается аномальная вариация плотностей $+/-0.04 \mathrm{r}_{\mathrm{cm}}^{3}$. Форма границы при моделировании варьировалась.

Информации о характере подошвы осадочного чехла (кровли кристаллического фундамента) недостаточно, чтобы её можно было бы учесть или заложить в плотностную модель в силу того, что мощность осадочного чехла по сейсмическим данным сильно варьирует по территории. Отдельными построениями она предполагается до глубин 20 км. Моделировать такие ситуации крайне затруднительно в силу того, что на глубинах более 5 км плотность

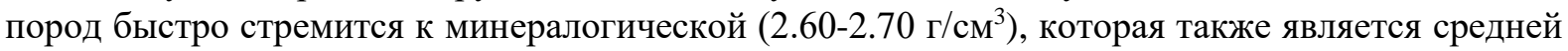
плотностью пород фундамента. В связи с этим, на фоне латеральных плотностных контрастов восстановление субгоризонтальной поверхности представляется сугубо субъективным процессом. Для минимизации субъективности решений введена плотностная, а не стратиграфическая граница таким образом, что мощность нижней части осадочного чехла оказывается постоянной и равной 5 км. На ней принят скачок плотностей $0.05 \Gamma / \mathrm{cm}^{3}$. При подборе в слое допускается аномальная вариация плотностей $+/-0.15$ г/ $\mathrm{cm}^{3}$. Форма границы при моделировании остается неизменной.

Поскольку выше кровли палеозоя плотностной эффект уже учтен, то выше и ниже неё принята

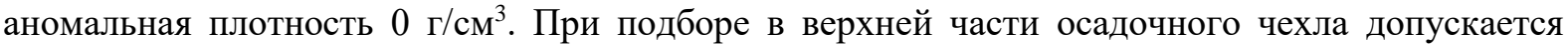

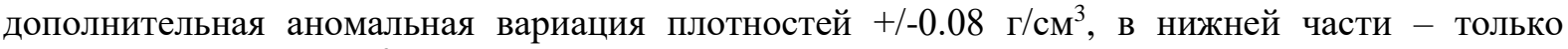

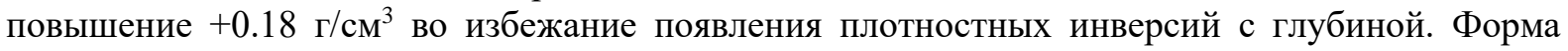
кровли палеозоя при моделировании остается неизменной.

Для минимизации неоправданно больших изменений плотностей в верхних слоях при моделировании выполняется единственное условие - подбор осуществляется от нижнего горизонта к верхнему, тем самым длиннопериодные аномалии учитываются глубокими горизонтами. К сожалению, при таком подходе модель будет «столбчатой», то есть неподобранные эффекты в нижних частях модели будут перетекать в верхние. Однако для моделирования рифтовых зон, к которым относится ЕХРП, такой подход является вполне приемлемым. 


\section{Геологические выводы на основе трехмерной плотностной модели}

В результате трехмерного плотностного моделирования решены следующие задачи:

- уточнена морфология ряда сейсмостратиграфических поверхностей;

- рассчитано остаточное гравитационное поле с вычтенными эффектами от границы Мохоровичича и базовых ряда сейсмостратиграфических поверхностей;

- даны оценки распределения аномальных плотностей для верхней части осадочного чехла (выше кровли палеозоя), палеозойского комплекса, в коре и верхней мантии.

Интеграция полученной трехмерной плотностной модели в геологические представления, сложившиеся к настоящему времени, позволила уточнить ряд глубинных особенностей структуры. В пределах ЕХРП выделена обширная Енисей-Хатангская рифтовая система, являющаяся восточным продолжением Колтогор-Уренгойской. Енисей-Хатангский рифт до долготы Янгодо-Горбитского выступа продолжается единой зоной, а восточнее распадается на три ветви, разделенные выступами фундамента. Ширина и простирание ветвей рифтовой системы меняются, что может свидетельствовать о неоднократных попытках поперечных тектонических расколов в процессе рифтообразования. Одна из таких наиболее интенсивных попыток раскола Сибирской платформы фиксируется в области между плато Путорана и Анабарским плато. Видимо, неудавшаяся попытка раскола привела к извержению мантийного вещества в междуречье Хеты и Котуя с образованием сложного структурно-тектонического узла - Гулинского интрузивного массива, сложное строение и происхождение которого до сих пор являлось предметом геологических дискуссий, особенно острых в связи с его рудоносностью.

Северная ветвь пытается разомкнуть Таймырский блок, отделяя Янгодо-Горбитский выступ. Итогом его тектонического воздействия является образование в коре Южно-Таймырского блока трещин восток-северо-восточного направления, которые проявлены линейными высокамплитудными аномалиями потенциальных полей.

Центральная ветвь огибает с юга Янгодо-Горбитский выступ и, разворачиваясь на север, утыкается в Таймырский блок.

Южная наиболее «агрессивная» ветвь рифтовой системы, идет вдоль северной границы Сибирской платформы. Она протягивается вплоть до широты острова Большой Бегичев и, в отличие от вышеописанных ветвей, скользит вдоль края Таймырского орогена, прослеживаясь в коре далее на восток серией трещин восточного простирания (зафиксированы узкими линейными аномалиями потенциальных полей) практически до зоны влияния структур Северного-Ледовитого Океана (СЛО).

\section{Библиография}

Афанасенков А.П., Лыгин И.В., Обухов А.Н., Соколова Т.Б., Кузнецов К.М. [2017] Объемная реконструкция тектонических элементов Енисей-Хатангской рифтовой системы по результатам комплексной геолого-геофизической интерпретации. Геофизика, 2, 60-70.

Сурков В.С., Варламов А.И., Ефимов А.С., Гришин М.П., Кузнецов В.Л., Старосельцев В.С., Лотышев В.И., Смирнов Л.В. [2007] Консолидированная кора платформенных областей Сибири. Разведка и охрана недр, 8, 3-9.

Кузнецов К.М., Оболенский И.В., Булычев А.А. [2015] Трансформации потенциальных полей на основе непрерывного вейвлет-преобразования. Вест. Моск. ун-та. Сер. 4. Геология, 6, 6169. 


\section{EAGE}

\section{References}

Afanasenkov A.P., Lygin I.V., Obukhov A.N., Sokolova T.B., Kuznetsov K.M. [2017] Volumetric reconstruction of the Yenisei-Khatanga rift system`s tectonic elements by integrated geologicalgeophysical interpretation. Geophysics, 2, 60-70.

Surkov V.S., Varlamov A.I., Efimov A.S., Grishin M.P., Kuznetsov V.L., Staroselcev V.S., Lotyshev V.I., Smirnov L.V. [2007] Consolidated crust platform areas of Siberia. Prospect and protection of mineral resources, 8, 3-9.

Kuznetsov K.M., Obolensky I.V., Bulychev A.A. [2016] Potential Field Transformation on the Basis of a Continuous Wavelet Transform. Moscow University Geology Bulletin, 71, 112-120. 